\title{
ADOLESCENTE MASCULINO BENEFICIÁRIO DO PROGRAMA BOLSA FAMÍLIA: CONHECIMENTO SOBRE O PROGRAMA NA FAMÍLIA ASSISTIDA
}

\author{
Teenage boys enrolled in the family allowance program: \\ knowledge of the program in the family assisted
}

\author{
Adolescente del sexo masculino con el beneficio del "programa \\ bolsa familia": su conocimiento del programa en la familia \\ asistida
}

Artigo Original

\section{RESUMO}

Objetivo: Identificar o conhecimento do adolescente masculino sobre o Programa Bolsa Família e o seu impacto na família assistida. Métodos: Trata-se de um estudo descritivo, exploratório, com abordagem qualitativa, realizado entre julho e setembro de 2014, em uma escola pública no município de Fortaleza, Ceará, BR, com 12 adolescentes beneficiários do Programa Bolsa Família. Para a coleta de dados, foi utilizada a entrevista semiestruturada e técnica de grupo focal. Os dados foram analisados por meio da análise de conteúdo, emergindo quatro categorias temáticas: Atendimento de pessoas de baixa renda; frequência escolar como principal estratégia; falta de priorização na promoção da saúde e prevenção de doenças; Programa Bolsa Família: impacto nas famílias assistidas. Resultados: Os resultados apontaram que os adolescentes reconhecem os efeitos positivos do programa nas famílias de baixa renda melhorando o poder aquisitivo, além de levar ao aumento da frequência escolar, diminuindo a evasão, porém em nenhum momento mencionaram que o programa objetiva a promoção da saúde e o apoio de políticas complementares. Conclusão: Verificase a necessidade de incrementar a saúde do adolescente masculino vinculado ao Programa Bolsa Família com foco na Promoção da Saúde de forma consolidada numa perspectiva de previsibilidade na agenda multiprofissional da Atenção Primária à Saúde.

Descritores: Programas Governamentais; Adolescente; Masculinidade; Avaliação em Saúde.

\section{ABSTRACT}

Objective: To identify the knowledge that teenage boys have about the Family Allowance Program (Programa Bolsa Familia) and its impact on the family assisted. Methods: This is a qualitative descriptive and exploratory study conducted between July and September 2014 in a public school in the city of Fortaleza, Ceará, Brazil, with 12 teenage boys enrolled in the Family Allowance Program. Data were collected using semi-structured interviews and the focus group technique. Data underwent content analysis, which yielded four thematic categories: Support for low-income people; school attendance as the main strategy; lack of priority in health promotion and disease prevention; impact on the families assisted. Results: The results showed that the teenage boys recognize the positive effects of the program on low-income families as it improves their purchasing power and leads to increased school attendance, reducing dropout rates; however, they did not mention that the program aims at health promotion and the support of complementary policies. Conclusion: There is a need to improve the health of the teenage boy enrolled in the Family Allowance Program with a focus on health promotion on a consolidated basis within a predictability perspective in the multiprofessional agenda of Primary Health Care.

Descriptors: Government Programs; Adolescent; Male; Health Evaluation.

\section{Núbia Maria Uchôa Barbosa ${ }^{(1)}$ Maria Albertina Rocha Diógenes $^{(1)}$ \\ Mariana Pompeu de Sousa ${ }^{(1)}$ Daniela Gardano Bucharles Mont'Alverne ${ }^{(2)}$}

Recebido em: 16/11/2015 Revisado em: 02/04/2016 Aceito em: 15/05/2016 


\section{RESUMEN}

Objetivo: Identificar el conocimiento del adolescente del sexo masculino sobre el "Programa Bolsa Família" y su impacto en la familia asistida por él. Métodos: Se trata de un estudio descriptivo, exploratorio, de abordaje cualitativo realizado entre julio y septiembre de 2014 en una escuela pública del municipio de Fortaleza, Ceará, Brasil con 12 adolescentes con el beneficio del "Programa Bolsa Família". Se utilizó la entrevista semiestructurada y la técnica de grupo focal para la recogida de datos. Los mismos fueron analizados a través del análisis de contenido del cual emergió cuatro categorías temáticas: asistencia a las personas de baja renta; frecuencia en la escuela como estrategia principal; no prioridad para la promoción de la salud y prevención de enfermedades; "Programa Bolsa Família". impacto para las familias asistidas. Resultados: Los resultados apuntan a que los adolescentes reconocen los efectos positivos del programa en las familias de baja renta con la mejoría del poder adquisitivo además de aumentar la frecuencia en la escuela, disminuyendo la evasión pero en ningún momento han mencionado que el programa tiene el objetivo de la promoción de la salud y el apoyo de políticas complementarias. Conclusión: Se verifica la necesidad de mejorar la salud del adolescente del sexo masculino con vinculo en el "Programa Bolsa Família" y foco en la Promoción de la Salud de manera consolidada en la perspectiva de previsibilidad en la agenda multiprofesional de la Atención Primaria de Salud.

Descriptores: Programas de Gobierno; Adolescente; Masculinidad; Evaluación en Salud.

\section{INTRODUÇÃO}

O Programa Bolsa Família (PBF) é um programa de transferência de renda, direcionado às famílias em situação de pobreza ou extrema pobreza, que pretende, com suas condicionalidades, reforçar o acesso das famílias beneficiárias às políticas de educação, saúde e assistência social, promovendo melhoria das condições de vida, bem como levar o poder público a assegurar a oferta desses serviços. O adequado acompanhamento dessas famílias possibilita a identificação de situações de vulnerabilidades entre os membros do contexto familiar ${ }^{(1)}$.

O adolescente, como membro da família e participante do PBF, também se encontra nessas condições de vulnerabilidade, pois a adolescência é uma etapa da vida entre a infância e a idade adulta, na qual o jovem se expõe a muitos conflitos, próprios da idade, em busca da identidade e pelas várias modificações corporais e comportamentais. Os limites cronológicos da adolescência são definidos entre 10 e 19 anos, divide-se em pré-adolescência, o período etário entre 10 a 14 anos e a adolescência propriamente dita, dos 15 aos $19 \operatorname{anos}^{(2)}$.
A pouca informação desse público adolescente diante dos novos problemas a serem enfrentados passa a ser objeto de intervenção dos serviços de saúde. Dessa forma, a promoção da saúde sugere um processo de produção do saber e das ações, tanto na área da saúde quanto na área de políticas públicas, por meio da construção e gestão compartilhada. É importante que na produção, análise e formulação de ações propostas para a melhoria da qualidade de vida de uma população sejam estabelecidas estratégias que contemplem a participação de todos os atores sociais envolvidos, tais como, os próprios adolescentes, os profissionais de saúde, os pais, os gestores dos serviços e outros $^{(3)}$.

Nessa conjuntura, a escola assume um papel de facilitador para o desenvolvimento de ações no âmbito de educação em saúde, sendo o ambiente estratégico para a concretização de iniciativas de promoção em saúde com adolescentes. A parceria realizada com as escolas considera-a como local onde o adolescente permanece a maior parte do tempo e abre espaço para se trabalhar, além de conhecimento, mudanças comportamentais e habilidades ${ }^{(4)}$.

Desse modo, espera-se, por meio deste estudo, contribuir para a ampliação do conhecimento sobre o assunto e fornecer subsídios e informações que possam ser relevantes para um melhor entendimento sobre os mecanismos governamentais de combate às desigualdades sociais envolvendo as políticas de saúde pública.

Portanto, os objetivos do presente estudo são identificar o conhecimento do adolescente masculino sobre o Programa Bolsa Família e o seu impacto na família assistida, tendo em vista as condicionantes do Programa e suas responsabilidades relacionadas ao cumprimento de ações na área da saúde, educação e assistência social para melhorar as condições de desenvolvimento da família, principalmente crianças e adolescentes do gênero masculino.

\section{MÉTODOS}

Tratou-se de um estudo descritivo, exploratório, com abordagem qualitativa, com adolescentes beneficiários do PBF, de uma escola pública estadual de educação profissional no município de Fortaleza, Ceará, BR, entre os meses de junho e julho de 2014.

A referida escola atende não só alunos da comunidade local, mas também de bairros adjacentes e da região metropolitana de Fortaleza, organizada em tempo integral que oferece o ensino médio integrado a 360 alunos, nos cursos de Edificações, Estética e Redes de Computadores, proporcionando ao jovem estudante a oportunidade de ser protagonista, empreendedor de sua história de vida, exercendo sua cidadania de forma autônoma e com formação para o mundo do trabalho. 
O encontro com os participantes do estudo se deu no período da tarde no auditório da escola. A amostra consecutiva não probabilística, por conveniência, composta por 15 adolescentes, porém somente 12 compareceram ao encontro proposto. Estes 15 adolescentes foram selecionados aleatoriamente das salas de aula, seguindo os critérios de inclusão do estudo: adolescentes do gênero masculino, vinculados ao PBF, com idade entre 15 a 19 anos (a adolescência propriamente dita) ${ }^{(2)}$, regularmente matriculados na instituição. Pelo fato de a pesquisa qualitativa não se basear em critérios numéricos para garantir o cálculo amostral e sua representatividade, considera-se a saturação das falas para definição do número de participantes a compor o grupo de indivíduos. É usada para estabelecer ou fechar o tamanho final de uma amostra em estudo ${ }^{(5)}$.

A coleta de dados deu-se mediante entrevista semiestruturada, na qual, inicialmente foram coletadas informações gerais e de saúde dos adolescentes com as variáveis: idade, peso, altura, nível de escolaridade, procedência e as informações de saúde. Buscou-se informações sobre visitas regulares à Unidade de Saúde, esquema vacinal e vida sexual. Para medida dos dados antropométricos, foi utilizada uma balança eletrônica, modelo $2003 \mathrm{~B}^{\circledR}$ e, para a estatura, utilizou-se o antropômetro vertical marca Tonelli $^{\circledR}$, aferidos, periodicamente, pela escola.

Em seguida, utilizou-se a técnica de grupo focal, que se deu por meio de um encontro com os adolescentes, com foco nas questões norteadoras que favoreceram o debate e o levantamento das informações para a elucidação dos objetivos propostos.

A técnica do grupo focal é um instrumento de coleta de dados no qual o pesquisador tem a possibilidade de ouvir vários sujeitos ao mesmo tempo, além de observar as interações características do processo grupal ${ }^{(6)}$. Para a realização do grupo focal, este deve ser composto por no mínimo seis e no máximo entre doze e quinze pessoas com tempo médio de noventa minutos, grupos maiores limitam a participação, as oportunidades de trocas de ideias e elaboração, o aprofundamento no tema e nos registros dos dados.

Assim, o desenvolvimento do grupo focal, deu-se em um encontro, seguiu um roteiro de debate elaborado a partir das seguintes questões norteadoras: 1) Que conhecimento você tem sobre o PBF? 2) De acordo com seus conhecimentos sobre o programa, quais são seus compromissos com o PBF? 3) O PBF dá oportunidades de discutir como prevenir doenças e cuidados primários com sua saúde? 4) Quais os impactos positivos e negativos do PBF?

Os registros do grupo foram realizados de duas formas, uma por gravação, com consentimento dos participantes e o outro, por um entrevistador que registrou em um diário de campo a linguagem não verbal dos participantes.

Após o encontro, as falas foram transcritas e em seguida os dados foram analisados com base na técnica de análise de conteúdo(7), que envolve uma renúncia a um número ambicioso de sujeitos, que se baseia em operações de desmembramento do texto em unidades, para posteriormente, realizar o seu reagrupamento em classes ou categorias. Aponta como pilares a fase da descrição ou preparação do material, a inferência ou dedução e a interpretação.

Dessa forma, seguiram-se as seguintes etapas para categorização dos dados: pré-análise; leitura flutuante das entrevistas; constituição do corpus; seleção das unidades de contexto e de registro; recorte; codificação e classificação; categorização e definições das categorias temáticas ${ }^{(7)}$. Após a leitura das entrevistas, visando aos objetivos propostos, emergiram quatro categorias, que foram analisadas de acordo com a literatura alusiva ao tema: Categoria I Atendimento de pessoas de baixa renda; Categoria II Frequência escolar como principal estratégia; Categoria III - Falta de priorização na promoção da saúde e prevenção de doenças; Categoria IV - Programa Bolsa Família: impacto nas famílias assistidas.

Para garantir o sigilo da identidade dos participantes, foram adotados os códigos "A" (A1, A2,... A12), relativo aos adolescentes que participaram da entrevista.

Todos os pais ou representantes legais que concordaram que seu filho participasse do estudo assinaram o Termo de Consentimento Livre e Esclarecido, e os adolescentes, o Termo de Assentimento Livre e Esclarecido. A presente pesquisa obteve aprovação do Comitê de Ética em Pesquisa com Seres Humanos da Universidade de Fortaleza (UNIFOR), sob parecer no 652.090, regido pela Resolução $466 / 12^{(8)}$.

\section{RESULTADOS E DISCUSSÃO}

Neste espaço, serão apresentados os dados relacionados às informações gerais e de saúde dos participantes do estudo para em seguida serem apresentadas as categorias temáticas emergidas do estudo.

Participaram do estudo 12 adolescentes masculinos, com idade média de $15,8 \pm 0,75$ anos, com peso médio de $62,01 \pm 7,17 \mathrm{~kg}$, altura média de $1,73 \pm 0,06 \mathrm{~m}$, todos cursando o segundo ano do Ensino Médio e cumprindo as condicionalidades na área da educação, ou seja, com frequência escolar acima de $85 \%$ do exigido pelo programa. Quanto à procedência, seis adolescentes são de Fortaleza$\mathrm{CE}$, e cinco de regiões metropolitanas, Caucaia e Maracanaú e um da cidade de São Paulo. 
Com relação aos dados relacionados à saúde destes adolescentes, nenhum costuma frequentar a Unidade de Atenção Primária à Saúde (UAPS) de seu bairro para acompanhamento de Crescimento e Desenvolvimento Puberal, porém apresentam carteira vacinal atualizada das vacinas dT adulto (difteria e tétano), anti- hepatite B e tríplice viral (Sarampo, Caxumba, Rubéola), vacinas essas recomendadas desde a infância e que fazem parte do calendário básico de vacinação do adolescente. Quanto aos aspectos relacionados à vida sexual, quatro adolescentes mencionaram ter vida sexual ativa e que utilizam preservativos. Dois adolescentes disseram participar de atividades sócio-educativas fora da escola.

Com relação ao tempo de recebimento do benefício do PBF, um não soube informar o tempo, um adolescente disse que faz um ano que recebe e os demais, auferem em média de 3 a 7 anos.

\section{Atendimento de pessoas de baixa renda}

Nessa categoria, os participantes entendem que o PBF é um complemento de renda, uma proposta do Governo Federal de tornar suas vidas melhores e reconhecem esse benefício. É perceptível por alguns adolescentes a utilização do recurso para a aquisição de alimentos e roupas. As falas dos discentes apontam família de baixa renda, pessoas com dificuldade de pagar as necessidades básicas, baseado na renda e no número de pessoas que vivem na casa.

Os relatos a seguir demonstram tais colocações:

"O Programa Bolsa Família é um programa que o governo nos propicia para ajudar contra a fome com aquelas famílias que não têm dinheiro. Aí isso ajuda muito no nosso dia a dia, a comprar roupa, alimento para a familia que está abaixo do nível". (A 8)

"Eu acho que o governo dá esse dinheiro para ajudar as pessoas a ter essa renda todos os meses, ajudar a comprar material da escola, que muitas pessoas não têm esse dinheiro por causa das despesas de casa!". (A 9)

Esse achado contrasta com pesquisa realizada no Brasil em $2008^{(9)}$ na qual $83 \%$ dos entrevistados evidenciaram que o objetivo do PBF era a manutenção das crianças na escola. Por outro lado, o objetivo de ajudar no combate à pobreza foi menos assinalado (65\%).

Em outra pesquisa realizada, em relação ao conteúdo temático das publicações, houve a predominância de pesquisas que não apontavam efeitos positivos e negativos conclusivos a respeito das contribuições do PBF no combate à pobreza. Há, no entanto, um esforço por parte dos pesquisadores no sentido de refletir e aprofundar a discussão sobre o tema ${ }^{(10)}$. Quando se analisa as estratégias de combate à pobreza, as de curto prazo, muitas famílias em situação de vulnerabilidade puderam ter suas necessidades amenizadas, favorecendo, em especial, aspectos relacionados à sobrevivência, como acesso à alimentação, ao vestuário e aos remédios ${ }^{(11)}$.

O pressuposto emancipatório dos programas de transferência de renda visa apoiar iniciativas para instituição de políticas públicas sociais visando promover a emancipação das famílias beneficiadas ${ }^{(12)}$.

Os resultados alcançados pelo PBF são promissores para o Estado, sobretudo no que diz respeito ao marketing político, econômico e social, pois, em tese, o governo está promovendo a inclusão e a emancipação social das famílias pobres e ou extremamente pobres, além de estar possibilitando o acesso e continuação dos filhos destas no sistema educacional, embora sejam questionáveis as condições de permanência e a qualidade do ensino a eles ofertada $^{(13)}$.

\section{Frequência escolar como principal estratégia}

A categoria aponta que todos os adolescentes entrevistados conhecem o cumprimento das condicionalidades na área da Educação, porém não mencionam a necessidade de o Programa se articular com outras políticas, como a de Promoção da Saúde e referente à saúde do adolescente masculino. Talvez por adoecerem pouco ou não tiveram informações relevantes do processo saúde/doença/cuidado e pela falta de conhecimento das inter-relações sujeito/família/profissional/sistema por parte dessa população tutelada, como também, pela falta da importância dos elos educação e saúde, como se observa:

"Eu acho assim, tem que respeitar a legislação do governo e não faltar na escola tem que estar presente quando puder que isso é tipo uma ajuda não é”. (A 7)

"É como se fosse uma espécie de investimento e para todo investimento você tem que ter um resultado. Então eu acho que não adiantaria, por exemplo, eles darem essa quantia para acabar o adolescente não indo para escola, que é assim, o adolescente pode ter várias oportunidades, mas sem dúvida a maior que ele tem são os estudos. E se ele não está se dedicando, acho que o investimento que o governo daria a ele seria em vão, caso não estivesse frequentando as aulas e se aprimorando". (A 12)

A presença obrigatória de crianças e dos adolescentes na escola e a concessão de benefícios reduzem as horas disponíveis para o exercício de trabalho infantil. Isto diminui a ociosidade deles e a possível delinquência ${ }^{(14)}$. É considerado trabalho infantil qualquer atividade laboral remunerada entre 5 a 17 anos. Entretanto, no ano de 2007, aproximadamente, 4,8 milhões de crianças e adolescentes, nessa faixa etária, possuíam alguma atividade laboral 
Brasil, prática ainda não banida da sociedade ${ }^{(15)}$. Portanto, um dos eixos do PBF é o de garantir a permanência dessas crianças na escola, para tentar, de alguma forma, melhorar suas aptidões para um trabalho no futuro mais qualificado e por consequência melhor remunerada ${ }^{(15,16)}$.

$\mathrm{Na}$ fala do discente A3, a frequência escolar é a condicionalidade mais preponderante e, com isso, atende o propósito do Programa de erradicação do trabalho infantil (PETI). Nesta declaração, pode-se perceber uma ênfase ao valor social da educação. No âmbito escolar, é o grupo que mais necessita da escola para obter sua educação ${ }^{(17)}$.

No entanto, nenhuma referência é feita ao desempenho educacional desses alunos, o que leva a questionar se a assiduidade, por si só, seria sinônimo de aprendizagem. $\mathrm{Na}$ Pesquisa Nacional por Amostra de Domicílios, 2014(18), no período de 2007 a 2014, foi mantida a tendência de declínio das taxas de analfabetismo e de crescimento da taxa de escolarização do grupo etário de 6 a 14 anos e do nível de educação da população. O diferencial por sexo persistiu em favor da população feminina. O nível de instrução cresceu de 2007 para 2014, sendo que as pessoas com pelo menos 11 anos de estudo, na população de 25 anos ou mais de idade, passou de 33,6\% para 42,5\%. O nível de instrução na população feminina foi mais alto que o masculino. Em 2014, no contingente de 25 anos ou mais de idade, a parcela com pelo menos 11 anos de estudo representava $40,3 \%$, para os homens e $44,5 \%$, para as mulheres ${ }^{(18)}$. Mas, esta referência trata do panorama nacional, não estando separadas, as crianças que são beneficiadas pelo PBF.

Reforça-se que a contrapartida ao benefício da renda concedida às famílias pelo PBF compreende a matrícula das crianças e adolescentes de 6 a 17 anos na escola, a frequência mínima de $85 \%$ nas aulas a cada mês e a obrigatoriedade de informar ao gestor do PBF qualquer mudança de escola. A definição dessas condicionalidades propõe a difícil missão de tentar romper com os ciclos de pobreza que marcam as gerações dessas famílias. No seu prefácio, o texto legal recomenda a concretização do direito à Educação como elemento fundamental da inclusão social das famílias, compreendendo a educação escolar como condição da construção de conhecimento, da formação humana e da proteção social às crianças e adolescentes ${ }^{(19)}$.

Em pesquisa realizada, as mães foram indagadas como elas avaliavam o PBF e Programa Bolsa Escola, e a exigência do mesmo em relação à frequência escolar. Do total, onze mães $(91,7 \%)$ o avaliaram como "bom", ressaltando que o benefício ajudava na compra de material escolar dos filhos e nas despesas da família. Apenas uma mãe $(8,3 \%)$ afirmou que era um incentivo, porém não deveria ser o motivo da ida da criança à escola. Com relação à assiduidade da criança na escola, três mães $(25,0 \%)$ não opinaram, enquanto nove delas $(75,0 \%)$ afirmaram concordar com a exigência. Desse modo, a prática comum passa a punir e castigar as famílias beneficiárias que apresentam esse tipo de comportamento, encarando-as como consequência de uma escolha racional de cada uma e não, como uma condição de vida que não oferece as condições sociais objetivas para o sucesso da vida escolar ${ }^{(13)}$.

\section{Falta de priorização na promoção da saúde e prevenção de doenças}

Em relação a essa categoria, promoção da saúde e prevenção de doenças no público adolescente, o entrevistado A4 apontou a precarização das ações de Promoção da Saúde contribuindo para a invisibilidade do adolescente masculino como beneficiário do PBF nas Unidades de Atenção Primária à Saúde e, "para melhorar a sua saúde", ele mencionou que depende de ações que sejam empoderadoras, participativas e com a presença de outros setores. Enquanto, o entrevistado A5 demonstra o desconhecimento dos princípios do Sistema Único de Saúde - SUS:

"Eu acho que melhorando o atendimento em postos e
hospitais. Se for comparar o dinheiro que a gente recebe
para ser usado na saúde, não vai dar para quase nada
e muitas vezes a gente vai em postos e hospitais e vê
médicos dormindo, sem querer atender em horário de
trabalho". (A 4)

[...] As pessoas não têm dinheiro para pagar um hospital particular e acaba que a saúde pior. Assim poderia aumentar no valor da renda se a pessoa quisesse contratar um serviço privado ou melhorar o atendimento nos postos". (A 5)

A Promoção da Saúde, como uma das estratégias de produção de saúde, ou seja, como um modo de pensar e de operar articulado às demais políticas e tecnologias desenvolvidas no sistema de saúde brasileiro, contribui na construção de ações que possibilitam responder às necessidades sociais em saúde. Entende-se, portanto, que a Promoção da Saúde é uma estratégia de articulação transversal na qual se confere visibilidade aos fatores que colocam a saúde da população em risco e às diferenças entre necessidades, territórios e culturas presentes no País, visando à criação de mecanismos que reduzam as situações de vulnerabilidade, defenda radicalmente a equidade e incorporem a participação e o controle sociais na gestão das políticas públicas ${ }^{(20)}$.

Em relação ao cuidado com a saúde, um detalhe relevante observado no grupo em estudo foi o fato de todos estarem com o esquema vacinal completo. Segundo o calendário de vacinação básica ${ }^{(21)}$, as vacinas para adolescente do sexo masculino são: dT, Tríplice viral, antihepatite B e Febre Amarela, entretanto para este grupo observa-se elevada mortalidade por causas externas e risco 
maior de morbidade para Aids, hepatites B e C, tuberculose, leptospirose e tétano acidental ${ }^{(22)}$.

Sobre esse assunto, podem-se ver os comentários de A11 e A12:

"O Bolsa Família, esse Programa poderia estar alertando mais algumas formas de prevenções, porque aqui na escola tem aula de projeto de vida e tem momento em que a gente fala de prevenções de vários tipos de doenças e quando você ouve [...] tem doenças que ninguém nunca ouviu falar e devido à gravidade você acaba ficando um pouco preocupado e busca saber mais". (A 11)

"Eu acho que muitos adolescentes deixam de procurar o posto de saúde e o hospital para se consultar para saber como está o corpo, é porque não tem tanto alerta! Não tem tantas prevenções por escrito, não é! Dizendo como é tratada assim a saúde e tudo. Enfim, acho que o programa poderia estar conscientizando o adolescente, em relação a isso". (A 12)

Pelas falas o estudo evidencia uma necessidade real de reformulação, para atender as deficiências deste grupo de vulneráveis. Vale ressaltar que em 2010 foram publicadas as diretrizes nacionais para a atenção integral à saúde de adolescentes e jovens na promoção, proteção e recuperação da saúde (PNAISAJ), em que se percebe a necessidade do aumento da discussão sobre a saúde do homem para além do paradigma biopsíquico, tendo em vista que as políticas públicas aparecem de forma diversificada e transversalmente no gênero masculino ${ }^{(23)}$.

A escola é o local que o adolescente permanece a maior parte do tempo, portanto deve ser um espaço para trabalhar conhecimentos, mudanças comportamentais e habilidades dos jogos. Uma pesquisa com adolescente entre 13 a 19 anos, sobre sexualidade observou que mais da metade dos jovens não demonstrava adequado conhecimento sobre o tema. Embora a maioria dos adolescentes afirmasse ter contato com o tema na escola e na família, eles reconhecem os amigos como principal fonte de influência ${ }^{(22)}$.

\section{Programa Bolsa Família: impacto nas famílias assistidas}

Nessa categoria, pode-se avaliar um impacto positivo do Programa pelo entrevistado A6.

"Eu acho que é ter uma renda a mais. Essa renda pode ser distribuída para educação do próprio adolescente. Servir pra fazer curso ou mais [...] E a própria saúde do adolescente" (A6)

Em pesquisa realizada no Brasil, em 2008, em relação à percepção sobre melhorias decorrentes do $\mathrm{PBF}$ na vida das pessoas, das famílias, das comunidades e da população, os dados indicaram que a concordância foi de pelo menos $68 \%$. No quesito que trata do uso do benefício, o mais frequentemente percebido foi a compra de mais alimentos $(79 \%)$ e de mais material escolar $(75 \%)$. Os itens sobre a aquisição de mais artigos de uso pessoal e de mais utensílios para o lar foram assinalados por aproximadamente $60 \%$ dos entrevistados ${ }^{(9)}$.

Os impactos do programa na saúde começam, agora, a apresentar razoável acúmulo de trabalhos, o que permite que certas conclusões possam ser confirmadas. Já se sabia que as famílias beneficiárias do programa reportam gastar seus recursos majoritariamente com alimentos, além de itens relacionados com educação e saúde ${ }^{(23)}$ fato que foi confirmado por outro estudo ${ }^{(24)}$ que sugere aumento de diversos grupos de alimentos analisados.

Por outro lado, a fala a seguir toca em um ponto importante, que para o entrevistado, tem impacto negativo no Programa:

"O Bolsa Família por um certo lado é bom, só que ele é tipo uma alienação. Quando uma pessoa recebe dinheiro, ela sente a firmeza de que aquilo sempre vai acontecer, ela não precisa se preocupar com outro dinheiro, tipo ela não precisa se preocupar porque o governo vai sempre ajudar. Só que ele vai ajudar em um pouco espaço de tempo. O trabalho também tem que vir. O governo ajuda, mas ajuda quem precisa daquele dinheiro, aqueles que não têm firmeza". (A 3)

Contudo, um dos aspectos mais relevantes do PBF chama atenção: o impacto que o tempo de participação no programa, associado ao valor do benefício, tem sobre a escolaridade $^{(25)}$. Com efeito, se um dos objetivos do Bolsa Família é aumentar a escolaridade dos filhos das famílias mais vulneráveis, para que eles tenham mais oportunidades futuras, há de se pensar em uma política continuada, que garanta os impactos devidos na correção da trajetória escolar destas crianças e jovens e na obtenção de bons resultados, consequentemente, com futuras oportunidades de empregos.

Já na fala a seguir, pode-se observar que A9 expõe um aspecto importante, no qual acha que é impacto negativo a dificuldade de controle do PBF:

"O governo não pesquisa aquelas famílias que precisam usufruir do dinheiro, tipo assim, ele dá o dinheiro e não pesquisa qual a familia ele vai dar, por exemplo, tem muita família que ganha mais de quatro salários mínimos e ganha esse dinheiro! O governo assim é um erro dar esse dinheiro pra essa familia que não precisa. E tem muita família aí carente, está praticamente na miséria e não ganha esse dinheiro! Acho um erro! "(A 9)

A fala desse adolescente chama atenção, uma vez que o benefício ainda foge ao controle dos gestores do Programa. Autores $^{(26)}$ afirmam que as informações dadas pelas famílias são fundamentais para construir um cadastro que retrate, fielmente, a realidade das pessoas em situação de pobreza 
no Brasil. Os dados declarados sobre renda demandam um cuidado maior, pois servirão como elemento essencial para a seleção de potenciais beneficiários para programas sociais e concessão de diversos benefícios ${ }^{(26)}$.

Paralelo a isso, a fiscalização do cumprimento das condicionalidades educacionais é feita pelas Secretarias Municipais de Educação e pelo Ministério da Educação e Cultura (MEC). Uma lista gerada a partir do cadastramento das famílias (através do CadUnico) com o nome dos beneficiários e seu respectivos "Números de Informação Social" (NIS) é repassada pelo MEC às escolas para que os diretores informem às Secretarias Municipais de Educação a frequência escolar dos beneficiários. Essas informações são repassadas posteriormente ao MEC e ao Ministério do Desenvolvimento Social (MDS). Esse processo é realizado bimestralmente, com exceção do período de férias escolares. Junto à frequência escolar, vem o motivo da falta, caso ela tenha ocorrido. Caso o motivo seja justificável (doença do aluno; óbito na família; inexistência de oferta do serviço educacional; impedimento de acesso à escola; e inexistência de atendimento para pessoa com deficiência) nenhuma sanção é sofrida. Se o motivo é desconhecido ou não justificável, providências são tomadas ${ }^{(27)}$.

Em relação à educação e à frequência escolar, em pesquisa realizada, os autores observaram que o PBF de fato aumentou a matrícula escolar dos beneficiários em Minas Gerais-MG-BR, principalmente dos adolescentes entre 15 e 17 anos, dos negros, dos moradores da área rural e das crianças e jovens do sexo masculino - grupos tradicionalmente com maiores taxas de reprovação e abandono. O que esse estudo e outros vêm mostrando é que o benefício do Bolsa Família, por meio de sua condicionalidade educacional, tem um efeito significativo na inclusão escolar e permanência dos beneficiários na escola. Entretanto, frequentar a escola não garante que o aluno aprenderá os conteúdos ensinados em sala de aula e conseguirá competir no mercado de trabalho por empregos mais qualificados e melhor remunerados. $\mathrm{O}$ que se observa no ensino básico público no Brasil é que apesar de as crianças e jovens frequentarem a escola, eles muitas vezes saem do Ensino Fundamental e Médio sem um bom domínio da leitura e da escrita ${ }^{(13)}$.

Assim, ainda que o PBF contribua para a inserção das crianças e jovens na rede de ensino, ele não se configura como uma política educacional que promova a superação do ciclo intergeracional da pobreza via educação, que pressupõe ações relativas à qualidade do ensino que extrapolam os aspectos limitados de incentivo seletivo embutidos na condicionalidade educacional do $\mathrm{PBF}^{(14)}$.

\section{CONSIDERAÇÕES FINAIS}

A frequência escolar é considerada como condicionalidade preponderante do PBF e coincidentemente a mais apontada pelos adolescentes do estudo. Assiduidade é mais enfatizada que o nível de aprendizagem, devendo, então, ser revista esta condicionante pelo Governo Federal.

Os adolescentes masculinos não compreendem as condicionalidades previstas em lei, ou seja, os princípios da Constituição Federal, do Estatuto da Criança e do Adolescente e do Sistema Único de Saúde, como também a política complementar de peso voltado para a adolescência chamada Política Nacional de Atenção Integral à Saúde de Adolescentes e Jovens (PNAISAJ).

Diante do exposto, faz-se pressupor que o adolescente masculino não recebe orientações básicas de saúde no seu contexto vivido em razão da sua pouca verbalização, do não adoecer com tanta frequência, da pouca visibilidade desse jovem na Atenção Primária à Saúde (APS), das fragilidades nas ações de Promoção da Saúde do Programa Bolsa Família e da falta de fortalecimento da cidadania e do olhar crítico por parte dos profissionais da equipe de saúde da família na implementação de novas práticas de cuidado aos sujeitos vinculados ao Programa.

Nesse contexto, é importante incentivar ao adolescente masculino vinculado ao PBF a explorar o espaço de Educação em Saúde que deve existir na Atenção Primária de Saúde com intuito de alcançar sua autonomia, apontando a PNAISAJ como instrumento de cidadania.

Portanto, vale ressaltar a necessidade de incrementar a saúde do adolescente masculino, sujeito com bastante vulnerabilidade, avançando bem melhor na área da saúde, com foco na Promoção da Saúde de forma consolidada, tendo um olhar mais crítico por parte da gestão do programa, assim numa perspectiva de previsibilidade na agenda multiprofissional da Atenção Primária à Saúde.

\section{REFERÊNCIAS}

1. Ximenes DA, Agatte JP. A gestão das condicionalidades do Programa Bolsa Família: uma experiência intersetorial e federativa. Inc Soc. 2011;5(1):11-9.

2. Ramos FRS, Pereira SM, Rocha CRM. Viver e adolescer com qualidade. In: Associação Brasileira de Enfermagem, organizadores. Adolescer: compreender, atuar, acolher: projeto acolher. Brasília: ABEN; 2001. p.19-32.

3. Silva VC, Santos MSS. Promoción de la salud por DENTESCOLA: facilidades y dificultades de relievepor los académicos y los profesionales de la salud. Horiz Salud Expr Enferm. 2010;2(1):22-37.

4. Camargo EAI, Ferrari RAP. Adolescentes: conhecimentos sobre sexualidade antes e após a participação em oficinas de prevenção. Ciênc Saúde Coletiva. 2009;14(3):937-46. 
5. Fontanella BJB, Ricas J, Turato ER. Amostragem por saturação em pesquisas qualitativas em saúde: contribuições teóricas. Cad Saúde Pública 2008; 24(1):17-27.

6. Silva JRS, Assis SMB. Grupo focal e análise de conteúdo como estratégia metodológica clínica-qualitativa em pesquisas nos distúrbios do desenvolvimento. Cad Pósgrad Disturb Desenvolv. 2010;10(1):146-52.

7. Bardin L. Análise de conteúdo. São Paulo: Edições 70; 2015.

8. Conselho Nacional de Saúde (BR), Comissão Nacional de Ética em Pesquisa. Resolução no 466 de 12 de dezembro de 2012. Diretrizes e normas reguladoras de pesquisa envolvendo seres humanos. Brasília: Ministério da Saúde; 2012.

9. Castro HCO, Walter MIMT, Santana CMB, Stephanou MC. Percepções sobre o Programa Bolsa Família na Sociedade Brasileira. Opin Pública. 2009;15(2): 333-55.

10. Freire VRBP, Silva SSC, Cavalcante LIC, Pontes FARP. Programa Bolsa Família como estratégia do combate à pobreza em dissertações e teses no Brasil. Estud Pesqui Psicol (Online) [Internet]. 2013 [acesso em 2016 Jun 10]. Disponível em: http://www.e-publicacoes.uerj.br/ index.php/revispsi/article/view/8603/6495

11. Freire VRBP, Silva SSC, Moura MLS, Pontes FAR, Borges JAR. Atividades acadêmicas e a rotina de crianças ribeirinhas participantes do Programa Bolsa Família. Psicol Teor Pesqui. 2013;29(2):159-66.

12. Ministério da Saúde (BR). Presidência da República. Lei $\mathrm{n}^{\circ} 10.836$, de 09 de janeiro de 2004 [acesso em 2015 Jun 17]. Disponível em: http://www.planalto.gov. br/ccivil_03/_ato2004-2006/2004/lei/110.836.htm.

13. Barbosa RPJ, Lima OG, Paiva AC. Programa bolsa escola: entre a assistência social e a política educacional. Revista FSA. 2014;11(4):101-19.

14. Scheeffer F, Johnson GA. As diretrizes do Programa Bolsa Família: uma análise crítica. Rev Avaliação Políticas Públicas. 2008;2(2):7-17.

15. Araújo GS. Programa Bolsa Família e o trabalho de crianças e adolescentes: limites e alcances [dissertação]. Uberlândia: Universidade Federal de Uberlândia; 2009.

16. Instituto Brasileiro de Geografia e Estatística (IBGE). Pesquisa nacional por amostra de domicílios: síntese de indicadores sociais - 2007. Rio de Janeiro: IBGE; 2008.

17. Fahel M, Canaan M, Cabral B, Bahia M. O impacto do programa Bolsa Família na inclusão educacional: análise da matrícula escolar. SER Social. 2012;14(30):98-126.
18. Instituto Brasileiro de Geografia e Estatística - IBGE. Educação [acesso em 2016 Jun 17]. Disponível em: http://brasilemsintese.ibge.gov.br/educacao.html?tmpl $=$ component\&print $=1 \&$ page $=$

19. Ministério do Movimento Social e Combate à Fome (BR). Movimento de Desenvolvimento Social. Portaria Interministerial $\mathrm{Mec} / \mathrm{Mds} \mathrm{n}^{\circ}$ 3.789, de 17 de novembro 2004 [acesso em 2016 Jun 17]. Disponível em: http:// www.mds.gov.br/cnas/legislacao/portarias/portariasinterministerial/2004-portaria-interministerial-3-7892004-11-17-estabelece-atribuicoes-da-frequeenciaescolar-no-programa-bolsa-familia.pdf/vie

20. Ministério da Saúde (BR). Relatório Final da $8^{\mathrm{a}}$ Conferência Nacional de Saúde. Brasília, 17 a 21 de março de 1986. [acesso em 2015 Jan 07]. Disponível em: http://conselho.saude.gov.br/biblioteca/relatorios/ relatorio_8.pdf

21. Governo do Estado do Ceará (BR), Secretaria da Saúde do Estado. Situação da Saúde no Ceará. Fortaleza: Secretaria da Saúde; 2012.

22. Marola CAG, Sanches CSM, Cardoso LM. Formação de conceitos em sexualidade na adolescência e suas influências. Psicol educ [Internet]. 2011 [acesso em 2016 Jun 17];33:95-118. Disponível em: http:// saudepublica.bvs.br/pesquisa/resource/pt/psi-56181

23. Lopez SB, Moreira MCN. Políticas Nacionais deAtenção Integral à Saúde de Adolescentes e Jovens e à Saúde do Homem: interlocuções políticas e masculinidade. Ciênc Saúde Coletiva. 2013;18(3):743-52.

24. De Bem Lignani J, Sichieri R, Burlandy L, SallesCosta R. Changes in food consumption among the Programa Bolsa Família participant families in Brazil. Public Health Nutr. 2011;14(5):785-92.

25. Simões AA. The contribution of Bolsa Família to the educational achievement of economically disadvantaged children in Brazil [dissertation]. Brighton: University of Sussex; 2012.

26. Baratta TCB, coordenador. Capacitação para implementação do Sistema Único de Assistência Social - SUAS e do Programa Bolsa Família - PBF. Rio de Janeiro: Brasília; 2008.

27. Santos LMP, Pereira LL, Soares MD, Santos FC, Guadagnin HSC, Santos SMC. Avaliação do Programa Bolsa Família em municípios de baixo Índice de Desenvolvimento Humano e cumprimento das condicionalidades de saúde. Rev Tempus Actas Saúde Coletiva. 2011;5(4):139-65. 
Endereço do primeiro autor:

Núbia Maria Uchôa Barbosa

Universidade de Fortaleza - UNIFOR

Avenida Washington Soares, 1321

Bairro: Edson Queiroz

CEP: 60811-905 - Fortaleza - CE - Brasil

E-mail: nuchoabarb@hotmail.com
Endereço para correspondência:

Daniela Gardano Bucharles Mont'Alverne

Universidade Federal do Ceará - UFC

Rua Major Weyne, 1440

CEP: 60.430-450 - Fortaleza - CE - Brasil

E-mail: daniela.gardano@hotmail.com 